\title{
Investment Behavior and Trade Returns of Individual Investor: Mediating Role if Financial Literacy
}

\author{
ZAIN ULLAH \\ Lecturer, City University of science and IT, Peshawar \\ PhD Scholar, Qurtuba University, Peshawar \\ Uzain15@yahoo.com \\ DR. SHAMS UR RAHMAN \\ Assistant Professor, Qurtuba University, Peshawar \\ SOHAIL KHALIL \\ Assistant Professor, Institute of Management Sciences, Peshawar \\ Sohail.khalil@imsciences.edu.pk
}

\begin{abstract}
The main objective of current study was to analyze the impact of representativeness and anchoring on the trade returns of individual investors with the mediating role of financial literacy. In this connection hypotheses were developed on the basis of behavioral finance literature. The data was collected on 5-point likert scale questionnaires which were adopted from various authors. The collected data was checked for reliability and correlation analysis and regression models were run. On the basis of results obtained from analysis the four hypotheses which were developed have been accepted. It was concluded that representativeness and anchoring has significant positive impact while the financial literacy has mediating impact on the trade returns of investors. It is recommended that more the financial literacy less risk of behavioral biases impact on investment thus investors should gain financial literacy for taking rational investment decision and good trade returns.
\end{abstract}

Keywords: investment behavior, mediation, financial literacy, anchoring, representativeness

\section{Introduction}

Financial management, international markets dynamics and the operations and trading activities of agents, either individual or institutions working in these financial markets are the central areas of interest chosen for empirical studies by countless number of scholars for decades. The thorough research studies have been emerged in a crucial arguments and debates between two groups the rationalist and behaviorist (Boeckx, 2010). The proponent of rationalist like William Sharpe, Eigen Fama, Markowitz, Kenneth Ronald French, Franco Modigliani, Merton Miller and Stephen Ross consider the stock market participants as rational. The investor whose decision has been based on concrete justifications, sound reasons, analysis and logic or the individuals whose decision has been driven by the expected utility maxim (Markowitz, 1959). While the behaviorist proclaims that stock market agents are so rational. In addition, the irrational investor is 
one whose investment decision is subject to emotions i.e. greed, fear, anxiety, cognitive biases that cause the individuals to draw conclusion on the bases of short term phenomena while investor's intentions might be for long term (Shefrin \& Statman, 2011). Most of the academic research in finance is based on the hypothesis of the investors' full rationality. Empirical results from the study in the field of finance was mostly seen mixed, but has not usually support the whole hypothesis of rationality and this is one of the basic and a fundamental assumptions of Efficient Market Hypothesis (EMH) and the theory of modern portfolio (Dreman \& Berry, 1995). In the current time period the enthusiasm of the financial academic researcher for the above hypothesis was seen much weaker. This kind of varying perception motivates the economist and the psychologist to carry such type of experimental researches which initiate irrationality of the human being. Researchers in the field of finance were encouraged to smash the rationality hypothesis and to be familiar with the neutral effects of a few psychological biases on the decision and reaction of the investors, \& subsequently the results of such type of decisions and reactions on the movements of stock price.

The decision making process is defined as the process of selecting a specific option or a specific alternative among different available options or alternatives. (Kaustia \& Torstila, 2011; Statman, 2000). Making a decision is a complex and a multistep process which includes the analysis of different technical, personal and a situational factor. Taking or making investment decision among alternatives is a difficult and a vital challenge to each and every investor. Some of the socio economic factors are age of the investor's similar education and the monthly incomes etc. while if we see on the technical side the investment decision can be derive from different financial models like efficient market hypothesis, the CAPM model and arbitrage pricing theory etc.

That's why cognitive psychology is consider to be more useful while making a decision process (Chandra, 2008). The results of the bull market form the period of 2004-2007 and the outcomes of the financial crises there was seen a lot of new focuses on investor irrationality. "Behavioral Finance is becoming an integral part of decision-making process because it heavily influences the investors' performance". (Banerjee \& Murphy, 2011), "An understanding of how our emotions feeling and cognitive dissonance result in irrational behavior is indispensable for any investor" (Parikh et al., 2013).

\section{Literature Review}

\subsection{Introduction}

This section proposal represents the key theories on which the current research has been based. Further it curtly reveals previous empirical studies on the most common behavioral biases that investors encounter while taking investment decision. In last the conceptual framework and proposed hypothesis are presented.

\subsection{Theoretical Review}

There are many theories that previous scholars has been attached and relate to behavioral finance in different context, The current research has been based on the following four theories, of which three theories i.e. decision, heuristics and prospect theories describes the investment behavior of investors while the market efficiency theory describes both investor and the stock market as well. Brief discussions of these theories are given in following sections. 


\subsubsection{Decision Theory}

The decision theory was proposed by Warner in 1968, which describes the human's actions. Warner decision theory has two versions the one is prescriptive version while the other is descriptive. The prescriptive version states that "people should choose an action that maximize the expected utility while in descriptive form Warner proclaimed that people does choose the action that maximize the expected utility".

\subsubsection{Heuristic Theory}

The heuristic theory introduce by Tversky and Kahneman (1981)asserts that people uses imperfect rule of thumb and mental short cuts in their decision making when facing complex environment and incomplete information or when the information are complete but to complex. Ritter (2003), investors uses heuristics in case of uncertainty, complex and abundant of information and bounded rationality on the bases of their experience, trial and error and stereotypes which in certain cases might be beneficial but expose investors to perpetrate mistake.

\subsection{The behavioral finance}

One of the pillars on which the behavioral finance has been based is the effect of agent's beliefs about economic decisions. In the chapter on decision under uncertainty it stated that the probability distribution of future events is known. However, Kahneman and Tversky affirm the phrases like "I believe that ..." or "I think that ..." show that this is not always the case. In many cases (if not most) individuals should structure these probabilities for themselves, based on their beliefs and preferences. Decisions under uncertainty, we can make an estimate of what is the expected value of each bet and learn about the results and the process of maximizing utility. However, in real life economic individuals do not receive such information but must build it using tools designed to estimate the probabilities of occurrence of uncertain events. The focus of behavioral finance suggests that, indeed, operators use tools to develop these matrices of probabilities; however, ensure that these do not produce consistent results with actual results and leads the individuals to take wrong decisions (Tversky \& Kahneman, 1974).

The problem with the structuring of subjective probabilities is that it is a process "similar to estimate physical dimensions as distance or size" (Tversky \& Kahneman, 1974). The human mind performs this process using a collection of heuristics and mental short cuts in the short term help make quick estimates. But these tools also tend to be inaccurate and misjudgments that potentially distort the result.

Several authors have explained and documented behavioral biases that lead to wrong decisions. Kahneman and Tversky were the first who introduced these effects in the world of psychology and applied them to the finance discipline. In early attempt they elevated the existence of 3 biases: representativeness, availability and anchoring (Tversky \& Kahneman, 1974). Subsequently, Barberis and Thaler (2003) explain biases of confidence level and optimism. Below is the basis behind these biases, and the effects that existence of these biases could bring at the time of the selection and structuring of portfolios.

\subsection{Representativeness}

This is one of the most studied effects in terms of how it determines changes in the behavior of the economic agent and how consistently it affects the the decision making process. 
This bias is important when an economic agent is asked to determine the probability that an object A is part of group B or A comes from B (Tversky \& Kahneman, 1974). In finance, individuals constantly answer questions of this style. What is the probability that object $\mathrm{X}$ has a positive outlook for growth? How much value will add asset $\mathrm{X}$ to my portfolio as an investment strategy? These questions must be asked each time the decision to purchase an asset is made. However, behavioral finance is interested in understanding the process that leads an agent to determine the probability assigned to these responses. Representativeness bias can be seen from multiple perspectives. However, the effect should be the same, economic individuals choose the option that better represents their relationship to the group described. Kahneman and Tversky produce a variety of sources of this bias in their work, as they generate the representation. First, they state that there is an insensitivity of the agent to probabilities of past results. To demonstrate this effect, a study is presented in which researchers tell the respondent that within a group there are 70 engineers and 30 lawyers and another group is inverted this figure.

Both groups are given an identical list of descriptions of individuals and it is noted that for both cases, the probability that each individual is a lawyer or engineer is almost identical, a clear violation of Bayes' theory (Tversky \& Kahneman, 1974). There is also a problem of insensitivity to sample size, which means that individuals tend to make decisions based on a very small sample of information. This effect leads the individuals to think about the existence of the effects as "hot hand" (basketball) or put too much trust in an investment analyst who had a good run. In the specific case of basketball Studies they have not gotten any existence of "hot hand " effect. (Gilovich, Vallone, \& Tversky, 1985). In the case where the information generation process is known (for example, it is a random walk) the effect commonly known as the "Gambler fallacy" is observed. This effect can be easily observed in the case of successive tosses of a coin. The probability that a coin landing "head" or "tail" is $1 / 2$ however, in successive tosses (say 5 times) the probability to fall one of the two sides is equal to $1 / 2 \mathrm{n}$ or $1 / 32(\mathrm{n}=5)$. An agent observed a sequence of 5 shots on the same side might think is an unlikely outcome (which would be correct) and that in the next toss the odds to come out the same result is less than $1 / 2$ (which is incorrect). This is the Gambler's fallacy, the assignment of minor probabilities of occurrence to a result when the sequence of information that is explaining it does not seem "fair".

\subsection{Anchorage}

This bias occurs when a person makes some estimate based on an initial reference point and, normally, any adjustment made to reach the final decision is usually wrong. (Tversky \& Kahneman, 1974). Consequently what happens is that the reference values used to start a calculation works as anchors for the decision. An example of this bias shows that by presenting the calculation of factorial 8 as a mental multiplication in the following way;

$1 * 2 * 3 * \ldots * 8$

An average result of 512 was obtained. However, when presented in an inverse manner; $8 * 7 * 6 * \ldots * 1$

The average result was 2250 . It is observed both results are deviated from the correct result which is 40,320.As a consequence, it could be suggested that the "anchoring" of 
the initial number causes a different adjustment for each case and it is also noted that in both cases the adjustment is inadequate. The effects of this bias in finance are innumerable. The effect of having reference numbers and not making the necessary calculations or having the inadequate tools can cause serious errors in the structuring of portfolios. This is especially true when estimates of future returns are made and portfolios are created according to these estimates. This can lead to overexposure to assets, and it's the risk-return ratio.

\subsection{The Financial Literacy}

The $1^{\text {st }}$ most significant studies concerned to the financial literacy were from the period of 1990s and these studies mostly motivate the decreasing rates of saving that had been observed in American households the growing efforts observe in these framework was such policies which promote recovery system. Among these works, we can mention the work of Bernheim \& Garrett (1996) both of them analyzed a survey result which was conducting in the period of 1994 between the individuals in a US the age of these individuals was in between 30 to 40 which consist both type of data i.e. demographic and the economic. Both of the authors conclude form their survey that the rate of saving among theses individuals increase with the passage of time when they going near to their retirement and also with education. (Bernheim ; Parikh et al., 2013) conduct a study to establish the effect of similar characteristic of the financial education. The results and outcomes which they conclude from their studies was that educational policies play a significant and important role in increasing the rate of saving among individuals at adulthood. If we study the work of (Lusardi and Mitchell 2006) both of the scholars collect data from the US (HRS) Health and Retirement Study for the period 2004, the levels of financial literacy among individuals over 50 years are analyzed .

The main conclusions that the authors obtain are, in the first place, that knowledge at a financial level (compound interest or inflation, for example) is really scarce and, Secondly there was a clear and a positive correlation between the financial knowledge and in the retirement plans. In addition those individuals which have a higher level of financial knowledge tends to invest their hard earn money in a sophisticated products such like stocks, bonds. Later on the same data was used by the (Lusardi \& Mitchell, 2007) examine the wealth accumulation of baby boom age group or generation in between 1950 to 1960. The results outcome of these scholars was same to that one who's worked in the period 2006 and that are a good retirement plan has appositive relation with the level of financial literacy. Both of the same scholars in their later work (Lusardi, Mitchell, \& Curto, 2009) confirm their outcomes by extending their analysis by using data which was collected from the ALP American Life Panel and these analysis also facilities the financial knowledge. Both of the authors conclude that financial knowledge is a key element for planning a retirement plans. And also conclude that this knowledge is seen higher in those individuals who have received any kind of training in their school or in their work place.

In summary, it can be affirmed, in the view of empirical and observed evidence prescribed by the above scholars and researchers carried out so far, that, in a significant enough way, literacy or financial education is a factor that must be taken into account in when analyzing the behavior of individuals with respect to investment and the saving decisions. Set this significance, in order for them to be informed in an informed way and 
knowing their consequences and risks, it is essential that the improvement of financial knowledge among the population is encouraged, especially among retail investors.

\subsection{Conceptual Framework}

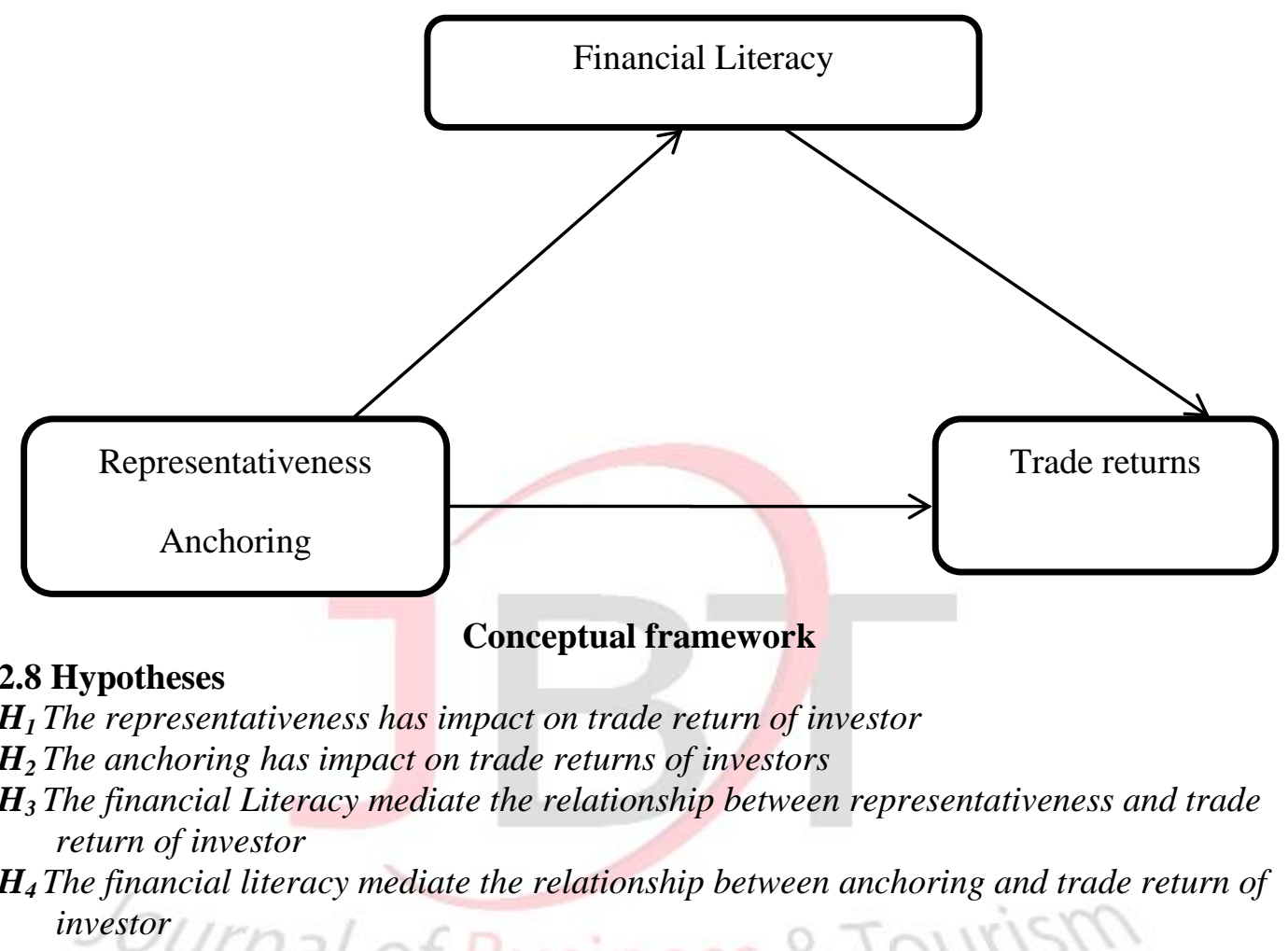

\section{Methodology}

The current research is quantitative in nature that used primary data which has been collected from individual investors through 5 point likert scale. The questionnaires were adopted from previous studies. The questionnaires of representativeness has been adopted from (Pompian (2011)), trade return, Le-Phuoc, Dao-Tran, Parreira, and Hauswirth (2011), financial literacy from (Van Rooij, Lusardi, \& Alessie, 2011) and anchoring from (Rau, 2015). The reliability of these entire items was validated in previous studies but for confirmation it was checked again. The reliability test Cronbach's alpha value of representativeness, anchoring, financial literacy and trade returns was $0.725,822,702$ and .788 respectively.

\section{Correlation Analysis}

Table 1: Correlation Analysis

\begin{tabular}{lllllll}
\hline \multicolumn{1}{c}{ Variables } & Mean & St Dev & 1 & 2 & 3 & 4 \\
\hline Representativeness & 3.5606 & .57718 & 1 & & & \\
Anchoring & 3.1302 & .65461 & $.282^{* *}$ & 1 & & \\
Financial literacy & 3.3036 & .56040 & $.457 * *$ & $.604 * *$ & 1 & \\
Trade returns & 3.3515 & .55933 & $.452^{* *}$ & $.504 * *$ & $.581^{* *}$ & \\
\hline
\end{tabular}

The correlation analysis reveals a strong and significant positive association among independent, mediating and dependent variables. The representativeness and anchoring 
are having positive association with mediating variable financial literacy having Pearson correlation values of .457 and .604 respectively, the significance value $p<0.001$ asserting a strong significant positive association. The mediating variable financial literacy also having a strong positive correlation with dependent variable trade return having correlation value of .581 and significance value $\mathrm{P}<0.001$. Again asserting a strong correlation between mediating and dependent variables.

\subsection{Regression Analysis}

Table 2: Regression Analysis

\begin{tabular}{|c|c|c|c|c|c|c|}
\hline \multicolumn{3}{|c|}{ Financial Literacy } & \multicolumn{4}{|c|}{ Trade Returns } \\
\hline Predictor & $\beta$ & $\mathrm{R}^{2}$ & $\Delta \mathbf{R}^{2}$ & $\beta$ & $\mathrm{R}^{2}$ & $\Delta \mathbf{R}^{2}$ \\
\hline Step 1 & & & & & & \\
\hline $\begin{array}{l}\text { Control variable } \\
\text { Step } 2\end{array}$ & .005 & & & .031 & & \\
\hline Representativeness & .284 & & & .290 & & \\
\hline Anchoring & .487 & .476 & 470 & .393 & .402 & .389 \\
\hline Mediation & & & & & & \\
\hline Step1 & & & & & & \\
\hline Control variable & & & & .031 & & \\
\hline Step2 & & & & & & \\
\hline Financial Literacy & & & & .583 & .367 & .336 \\
\hline
\end{tabular}

$\mathrm{N}=176$, Control Variables: Age, and Gender,

The two regression model i.e. regression and mediating regression was run to analyze the association and impact of independent variable representativeness and anchoring, mediating variables financial literacy and dependent variable trade returns of individual investors. In this regards the hypotheses were developed on the basis of previous literature data was collected and analyzed and hypotheses were tested. On the basis of results obtained from the regression both the independent variables are having strong and significant impact on the dependent variable trade returns of individual investors having beta values of .284 and .487 respectively and $p$ values of $<0.05$ asserting that representativeness and anchoring has significant positive impact on trade performance leading to the acceptance of $\mathrm{H} 1$ and $\mathrm{H} 2$. These result are quite align with Barberis and Thaler (2003)

Table 3: Mediation Regression Analysis

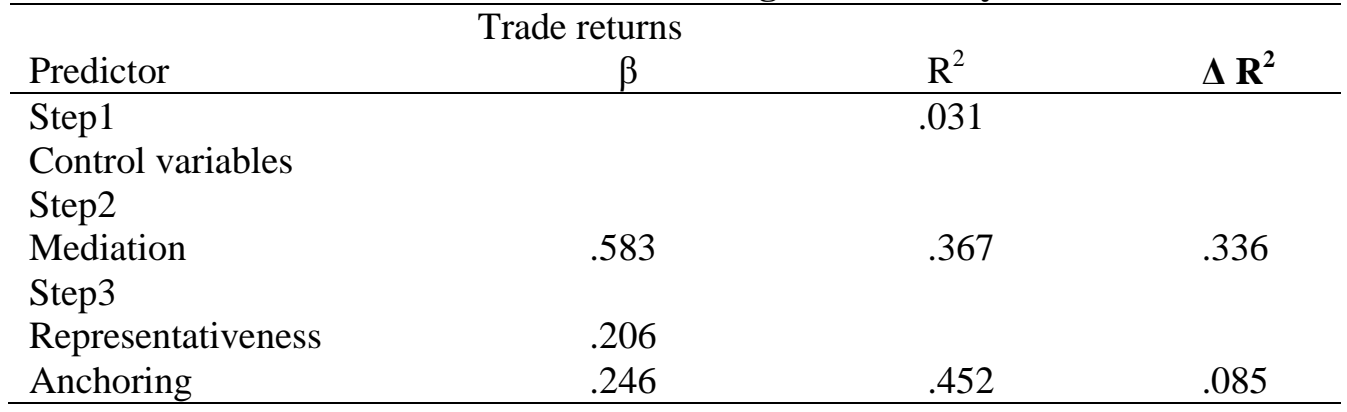

\section{N =176, Control variable: Age, and Gender}

For testing the third and fourth hypotheses the mediation regression was run after controlling the controlled variables the and adding the mediating variable financial 
literacy the independent variables decreased in their magnitude of explaining variation in dependent variable trade returns but still remains significant. According to Kenny (2008) if the coefficient values of independent variables decreased after employing mediating variable it will be a partial mediation and if the betas of independent variables became insignificant it will be full mediation but according to (Preacher \& Hayes, 2008) the mediation means change in the magnitude of independent variables after employing the mediating variable and there is no space for full and partial mediation. Thus in both cases out third and fourth hypothesis have accepted. It is concluded that financial literacy mediate the relationship among representativeness, anchoring and trade returns of the individual investor.

\section{Discussion and Conclusion}

The main objective of current study was to analyze the impact of representativeness and anchoring on the trade returns of individual investors with the mediating role of financial literacy. In this connection hypotheses were developed on the basis of behavioral finance literature. The data was collected on 5-point likert scale questionnaires which were adopted from various authors. The collected data was checked for reliability and correlation analysis and regression models were run. On the basis of results obtained from analysis the four hypotheses which were developed have been accepted. It was found that representativeness and anchoring both have significant positive impact on trade performance of investors. Further when check for mediation effect of financial literacy we found a meditational effect of financial literacy as well. It is to be make clear that independent variable i.e. representativeness and anchoring are having significant positive impact on trade returns of investor when these two variables were regressed on the dependent variable trade returns of individual investors. Additionally when the mediating variable financial literacy was added to model as mediating variable, the two independent variables representativeness and anchoring was still having significant impact of the trade returns of investors but their level of magnitude decreased. In direct regression the betas of representatives and anchoring were .284 and .487 , but when the financial literact mediating variable was added to model these betas reduced to .206 and .246. which according to(Hayes (2009); Preacher \& Hayes, 2008) means there is a mediation effect of financial literacy between independent and dependent variable. The literature asserts that financial literature investors are more rational and are not as expose to incorporation of behavioral biases in their investment decision as the illiterate investors our result confirms these results and it is because the literate investors are aware of emotional discipline in investment.

\subsection{Recommendation}

The current was done with sample of Khyber Pukhtunkhwa (KPK) investors which are not so much in numbers and also not so much aware of investment strategies and knowledge, further the current study investigated the individual investor's behavior. It is recommended for future research to carry out the same study with respondent from all over Pakistan, moreover the mediating role of financial literacy among Overconfidence, Bias Blind Spot and investment decision of investor. 


\section{References}

Banerjee, S., \& Murphy, J. H. (2011). Do rational demand functions differ from irrational ones? Evidence from an induced budget experiment. Applied Economics, 43(26), 3863-3882.

Barberis, N., \& Thaler, R. (2003). A survey of behavioral finance. Handbook of the Economics of Finance, 1, 1053-1128.

Bernheim, B. D., \& Garrett, D. M. (1996). The determinants and consequences of financial education in the workplace: Evidence from a survey of households: National Bureau of Economic Research.

Bernheim, G. Maki (1997):"Education and saving: the long-term effects of high school financial curriculum mandates.". NBER Working Paper Series, 6085.

Boeckx, C. (2010). Language in cognition: Uncovering mental structures and the rules behind them: John Wiley \& Sons.

Chandra, A. (2008). Decision making in the stock market: Incorporating psychology with finance.

Dreman, D. N., \& Berry, M. A. (1995). Analyst forecasting errors and their implications for security analysis. Financial Analysts Journal, 51(3), 30-41.

Gilovich, T., Vallone, R., \& Tversky, A. (1985). The hot hand in basketball: On the misperception of random sequences. Cognitive psychology, 17(3), 295-314.

Hayes, A. F. (2009). Beyond Baron and Kenny: Statistical mediation analysis in the new millennium. Communication monographs, 76(4), 408-420.

Kaustia, M., \& Torstila, S. (2011). Stock market aversion? Political preferences and stock market participation. Journal of financial economics, 100(1), 98-112.

Kenny, D. A. (2008). Reflections on mediation. Organizational research methods, 11(2), 353-358.

Le-Phuoc, D., Dao-Tran, M., Parreira, J. X., \& Hauswirth, M. (2011). A native and adaptive approach for unified processing of linked streams and linked data. Paper presented at the International Semantic Web Conference.

Lusardi, A., \& Mitchell, O. S. (2006). Baby boomer retirement security: The roles of planning, financial literacy, and housing wealth: National Bureau of Economic Research.

Lusardi, A., \& Mitchell, O. S. (2007). Baby boomer retirement security: The roles of planning, financial literacy, and housing wealth. Journal of monetary Economics, 54(1), 205-224.

Lusardi, A., Mitchell, O. S., \& Curto, V. (2009). Financial literacy among the young: Evidence and implications for consumer policy: National Bureau of Economic Research.

Markowitz, H. (1959). Portfolio Selection, Efficent Diversification of Investments: J. Wiley.

Parikh, N., Swarup, S., Stretz, P. E., Rivers, C. M., Lewis, B. L., Marathe, M. V., . . . Chungbaek, Y. (2013). Modeling human behavior in the aftermath of a hypothetical improvised nuclear detonation. Paper presented at the Proceedings of the 2013 international conference on Autonomous agents and multi-agent systems. 
Pompian, M. M. (2011). Behavioral finance and wealth management: how to build optimal portfolios that account for investor biases (Vol. 667): John Wiley \& Sons.

Preacher, K. J., \& Hayes, A. F. (2008). Asymptotic and resampling strategies for assessing and comparing indirect effects in multiple mediator models. Behavior research methods, 40(3), 879-891.

Rau, H. A. (2015). The disposition effect in team investment decisions: Experimental evidence. Journal of Banking \& Finance, 61, 272-282.

Shefrin, H., \& Statman, M. (2011). Behavioral finance in the financial crisis: market efficiency, Minsky, and Keynes. Santa Clara University, November.

Statman, M. (2000). Socially responsible mutual funds (corrected). Financial Analysts Journal, 56(3), 30-39.

Tversky, A., \& Kahneman, D. (1974). Judgment under uncertainty: Heuristics and biases. Science, 185(4157), 1124-1131.

Tversky, A., \& Kahneman, D. (1981). The framing of decisions and the psychology of choice. Science, 211(4481), 453-458.

Van Rooij, M., Lusardi, A., \& Alessie, R. (2011). Financial literacy and stock market participation. Journal of Financial Economics, 101(2), 449-472. 